\title{
Peningkatan Potensi Produk Unggulan Kabupaten Bandung Melalui Manajemen Produk dan Branding Digital
}

\author{
Astri Wulandari', Bethani Suryawardani ${ }^{2}$, Dedy Rahman Wijaya ${ }^{3}$, Siska \\ Komala Sari $^{4}$, Suryatiningsih ${ }^{5}$ \\ 1,2,3,4,5 Fakultas Ilmu Terapan, Universitas Telkom, Bandung, Indonesia \\ Email : astri.wulandari@tass.telkomuniversity.ac.id ${ }^{1}$, bethani@tass. \\ telkomuniversity.ac.id², dedyrw@tass.telkomuniversity.ac.id ${ }^{3}$, \\ siska@tass.telkomuniversity.ac.id ${ }^{4}$, suryatiningsih@tass.telkomuniversity.ac.id ${ }^{5}$
}

\begin{abstract}
ABSTRAK
Hanya 10\% dari total anggota Paguyuban Usaha Kecil Menengah Regional Kabupaten Bandung (PPKM) yang sudah menggunakan website dalam promosi penjualan produk yang diproduksi. Sedangkan sisanya 90\% masih menggunakan media konvensional untuk mempromosikan produknya, seperti penggunaan brosur dan pameran. Adapun data keanggotaannya juga masih dikelola dan disimpan hanya menggunakan software aplikasi microsoft excel, sehingga data anggota tersebut belum berelasi satu sama lain, tidak up to date dan berpotensi mengakibatkan inkonsistensi dan duplikasi. Dengan dibangunnya website profil Organisasi Komunitas UMKM berbasis Content Management System yang menampilkan informasi profil produk dan anggota, serta diadakannya pelatihan pengelolaan konten informasi tersebut menjadi solusi yang tepat dalam mengatasi permasalahan pengelolaan data anggota dan aktivitas promosi produk serta juga dapat mengembangkan kemampuan kewirausahaan melalui website, sehingga mereka tidak perlu bergantung hanya pada kegiatan jual beli secara tatap muka langsung (offline). Adapun pembangunan web tersebut dilaksanakan melalui Kegiatan Pengabdian kepada Masyarakat yang diselenggarakan oleh tim dosen dan mahasiswa Fakultas Ilmu Terapan (FIT) beserta Fakultas Komunikasi dan Bisnis (FKB) Universitas Telkom. Dengan disediakan website ini, diharapkan pengelolaan data anggota menjadi tersentralisasi dan lebih berkualitas serta kegiatan promosi produk unggulan di Kabupaten Bandung dapat menjangkau pasar yang lebih luas lagi.
\end{abstract}

Kata Kunci: digital branding; manajemen produk; produk unggulan.

\section{Increasing the Potential of Superior Products in Bandung Regency through Product Management and Digital Branding}

\begin{abstract}
All members of Bandung Regency Small and Medium Enterprises Association (PPKM), only 10\% have a website to improve the products produced. The rest (90\%) still uses conventional media such as brochures and exhibitions in the competition for their products. Coverage data is still managed using Microsoft Excel so that the data is not related, still requires inconsistencies and duplication, also not up to date. Development of a MSME Community Organization profile website based on a Content Management System that provides product profiles and member profiles, as well as content training that is appropriate to overcome difficulties in managing member data and product promotion and can increase entrepreneurial skills through the website. The web development is carried out through Community Service Activities conducted by lecturers and students of the
\end{abstract}


Faculty of Applied Sciences (FIT) and the Faculty of Communication and Business (FKB) Telkom University. With this website, it is hoped that promotional products can buy a wider market and data management for members is centralized and of better quality.

Keyword: digital branding; product management; featured product.

\section{PENDAHULUAN}

Hampir kebanyakan waktu yang digunakan untuk mencari produk dan jasa yang dibutuhkan konsumen adalah menggunakan internet (Nugraha dan Wahyuhastuti, 2017). Saat ini kegiatan bisnis sudah memasuki era digitalisasi, sehingga para pelaku usaha kecil dan menengah juga perlu untuk turut ikut serta mengimplementasikannya agar bisnis mereka tidak ketinggalan zaman dan selalu up to date mengikuti tren perkembangan zaman. Salah satu caranya yaitu dengan memunculkan informasi produk dan jasa mereka melalui sebuah website, sehingga dapat menjadi dasar perbandingan bagi konsumen ketika hendak membeli sebuah produk. Menurut Arifanty (2018), ada beberapa benefit yang bisa diambil oleh usaha kecil dan menengah melalui website yang dimiliki sendiri yaitu kredibilitas (dianggap lebih tinggi nilainya oleh konsumen dibanding yang tidak punya), pengembangan merek (merek adalah entitas bisnis yang menjelaskan tentang bisnis dan produknya dan yang akan tinggal di benak konsumen), pemasaran (pemasaran secara online dengan SEO dan pemasaran digital dapat membuat bisnis kecil dan menengah memiliki ranking yang tinggi), kompetisi (terutama pada konsumen online hanya percaya pada perusahaan yang memiliki website), dan kontrol (pemilik website dapat mengendalikan apa yang orang dapat lihat dan bagaimana persepsi mereka atau konsumen tersebut). Usaha kecil dan menengah juga sudah semakin global karena beberapa konsumen mereka memang berada di luar negara Indonesia (Sudarwati dan Satya, 2013).

Safitri (2016) menjelaskan untuk kemudahan masyarakat sasar dalam melengkapi dokumen berupa proposal, diperlukan sebuah aplikasi berbasis web yang dapat mengotomatisasi pembuatan proposal. Mitra binaan hanya mengisikan data penting tanpa perlu dibebani dengan kontekstual proposal. Dengan alasan tersebut maka tepatlah jika aplikasi berbasis web menjadi solusinya.

Selain aplikasi berbasis web, dengan adanya pelatihan dan workshop manajemen produk dan merk (labelling, logo, packaging dan strategi merk), serta pengembangan media branding, hal ini mampu meningkatkan kualitas produk agar memiliki nilai jual yang tinggi dan mampu bersaing dengan produk sejenisnya di masyarakat luas (Mahmudi dan Suryandani, 2018).

Menurut Budiarto et al. (2018), untuk meningkatkan kondisi ketahanan pangan dan kesejahteraan masyarakat, Dinas Ketahanan Pangan membidik kelompok sasar sebagai berikut. Keluarga miskin dan perempuan kepala rumah tangga miskin; Para ibu-ibu Rumah Tangga/ Tim Penggerak PKK; Pengrajin/ 
pengolahan pangan lokal; serta Usaha Kecil Menengah (UKM).

Kelompok sasar yang terbentuk dan mendapatkan pembinaan serta pendanaan ini kemudian diberi nama Kelompok Wanita Tani (KWT). Menurut Nurlina et al. (2017), KWT sebagai mitra binaan Dinas Ketahanan Pangan bertujuan mewujudkan kemandirian pangan melalui Kawasan Rumah Pangan Lestari (KRPL). KRPL merupakan program pemerintah untuk masyarakat dalam hal pemanfaatan perkarangan rumah dan hal ini dapat menambahkan upaya intensifikasi pemanfatan pagar hidup, jalan desa, dan fasilitas umum lainnya, lahan terbuka hijau serta mengembangkan pengolahan dan pemasaran hasil (Purwantini et al., 2016). Saat ini terdapat 84 (delapan puluh empat) KWT dan UKM olahan pangan yang dibina oleh Dinas Ketahanan Pangan. Jumlah tersebut berdasarkan data anggota yang aktif dan berhasil di data oleh Dinas Ketahanan Pangan. Jumlah mitra binaan ini seperti penomena gunung es, yaitu hanya sebagian kecil yang tercatat, padahal masih sangat banyak yang tidak tercatat karena lemahnya upaya administratif dan koordinasi pengelolaan data dari kepengurusan yang lama. Dinas Ketahanan Pangan juga mencatat terdapat 64 (enam puluh empat) produk olahan hasil diversifikasi KWT dan UKM untuk menciptakan keanekaragaman pangan agar dapat berpotensi menjadi produk unggulan Kabupaten Bandung.

Berdasarkan hasil wawancara dengan Kepala Bidang Konsumsi dan Keamanan Pangan ditemukan pemasalahan sekaligus kebutuhan sebagai berikut:

1. Dinas Ketahanan Pangan perlu melakukan pembinaan terhadap masyarakat di berbagai wilayah Kabupaten Bandung untuk meningkatkan kemandirian pangan.

2. Belum adanya pemerataan pembinaan oleh Dinas Pangan terhadap kelompok petani maupun UMKM di wilayah Kabupaten Bandung.

3. Kelompok petani mengalami kesulitan secara administratif dalam menyusun proposal untuk mendapatkan dana pembinaan dari Dinas Pangan.

4. Secara berkala Dinas Pangan melakukan monitoring terhadap mitra binaan. Saat ini belum tersedia pengelolaan data mitra binaan secara terpusat, sehingga menyulitkan Dinas Pangan dalam melakukan monitoring keberlanjutan program di masingmasing mitra.

5. Penyediaan data statistik dari produk, jenis produk, dan informasi mitra binaan merupakan kebutuhan yang setiap saat diperlukan oleh berbagai pihak yang berkepentingan, baik dari kalangan pemerintahan ataupun swasta.

6. Terdapat produk-produk unggulan yang dihasilkan oleh UMKM, KWT dan produk rumah tangga di Kabupaten Bandung yang belum banyak dikenal oleh masyarakat luas. 
7. Masyarakat belum mempunyai kesadaran mengenai kandungan bahan makanan sehat berbahan dasar non beras non terigu, salah satunya yaitu tepung mokaf (modifikasi cassava) yang memiliki kandungan gizi lebih tinggi dari terigu.

8. Belum adanya brand awareness mengenai produk-produk unggulan yang dihasilkan oleh UMKM, KWT dan produk rumah tangga di Kabupaten Bandung, sehingga perlu adanya manajemen produk dan merk (labelling, logo, packaging dan strategi merk), serta perlunya pengembangan media branding.

\section{METODE PENELITIAN}

Bentuk pengabdian masyarakat yang dilakukan adalah pelatihan keilmuan yang memberikan nilai tambah bagi masyarakat. Tahapan pelaksanaan kegiatan dilakukan dengan memberikan materi setelah itu pada sesi akhir adalah sesi tanya jawab. Adapun metode pelaksanaan yang dilaksanakan meliputi tahapan sebagai berikut:

1. Pengumpulan data. Menurut ParamitadanKristiana(2013), data dibutuhkan untuk mendapatkan gambaran konsisi existing dengan melakukan wawancara dan Forum Group Discussion (FGD) dengan Pengurus PPKM. Dengan teknik tersebut diperolah data berupa:
a. Profil PPKM dan anggotanya;
b. Struktur dan format data anggota yang dimiliki oleh

\section{PPKM;}

c. Permasalahan yang dihadapi PPKM dalam pengelolaan data dan profil anggota;

d. Kebutuhan fungsionalitas/ fitur yang harus dimiliki oleh website untuk pengelolaan data dan profil anggota ataupun pengurus PPKM.

2. Analisis dan perancangan website dilakukan untuk:

a. Menggambarkan setiap proses bisnis as-is guna dievaluasi sehingga diperoleh gambaran lengkap kondisi saat ini dan untuk identifikasi permasalahan yang terjadi;

b. Mengidentifikasi kebutuhan fungsionalitas sebagai acuan dalam menentukan fitur yang harus dimiliki oleh website yang dibangun;

c. Memodelkan fungsionalitas;

d. Membuat rancangan database;

a. Membuat rancangan interface

3. Pembangunan, Pengujian, dan dokumentasi website. Tahapan ini merupakan tahap pembuat coding program untuk membangun website berdasarkan rancangan yang telah dibuat; menguji aplikasi untuk memastikan semua fungsionalitas berjalan secara valid; dan mendokumentasikan website untuk menghasilkan buku panduan penggunaannya.

4. Sosialisasi penggunaan aplikasi. Tahap ini dilakukan untuk melatih semua pengguna agar dapat menggunakan website dan mensosialisasikannya kepada 
pihak-pihak yang berkepentingan (seperti dinas pemerintah terkait).

5. Membuat penyuluhan bagi masyarakat luas baik melalui media cetak maupun elektronik untuk meningkatkan kesadaran mengenai kandungan bahan makanan sehat berbahan dasar non beras non terigu, salah satunya yaitu tepung mokaf (modifikasi cassava) yang memiliki kandungan gizi lebih tinggi dari terigu.

6. Pelatihan dan workshop. Manajemen produk dan merk (labelling, logo, packaging dan strategi merk), serta pengembangan media branding.

\section{HASIL DAN PEMBAHASAN}

Berdasarkan pemasalahan mitra makadiusulkansolusipenyelesaiannya sebagai berikut:

1. Mengembangkan serta membangun aplikasi berbasis web untuk calon mitra binaan yang dapat membantu pengajuan proposal kepada Dinas Pangan secara otomatis.

2. Menyediakan pengelolaan sistem database terintegrasi dan terpusat, sehingga memudahkan Dinas Pangan dalam melakukan monitoring mitra binaan di wilayah Kabupaten Bandung agar terwujudnya kemandirian pangan bagi masyarakat.

3. Penyediaan data statistik dari jenis produk, dan informasi mitra binaan kewilayahan lainnya merupakan kebutuhan yang setiap saat dibutuhkan oleh berbagai pihak yang berkepentingan, baik dari kalangan pemerintahan ataupun swasta. Solusinya, diperlukan aplikasi yang memiliki fitur yang mampu menampilkan dashboard bagi penggunanya dengan dilengkapi data dan infografis yang dapat diunduh dalam berbagai format sesuai kebutuhannya.

4. Memberikan pelatihan dan workshop mengenai menajemen produk dan manajemen merk (labelling, logo, packaging, dan strategi merk) yang dapat membantu mitra binaan dalam rangka meningkatkan daya tarik produk-produk unggulan sehingga memiliki nilai jual yang tinggi dan dikenal oleh masyarakat luas.

5. Memberikan penyuluhan kepada masyarakat melalui berbagai media baik cetak maupun elektronik untuk meningkatkan kesadaran mengenai kandungan bahan makanan sehat berbahan dasar non beras non terigu, salah satunya yaitu tepung mokaf (modifikasi cassava) yang memiliki kandungan gizi lebih tinggi dari terigu.

6. Membantu pengembangan media branding bagi mitra binaan Dinas Pangan.

Adapun target luaran yang dihasilkan dari program pengabdian masyarakat ini yakni sebagai berikut:

1. Aplikasi berbasis web untuk mengelola database mitra binaan Dinas Pangan yang siap diimplementasakan. 
2. Terlaksananya kegiatan sosialisasi dan pelatihan penggunaan aplikasi berbasis web kepada mitra binaan dan Dinas Pangan dalam bentuk presentasi dan modul pengoperasian aplikasi.

3. Meningkatnya pemahaman mitra binaan dalam hal manajemen produk dan merk sehingga produk yang dihasilkan memiliki nilai jual yang tinggi.

4. Meningkatnya pemahaman dan kesadaran masyarakat tentang makanan sehat berbahan dasar tepung mocaf.

5. Terciptanya media branding yang tepat dan menarik.

6. Penulisan artikel ilmiah dalam bentuk publikasi popular pada media online.

Evaluasi dilakukan untuk memastikan semua tahapan pada metode pengerjaan dapat terlaksana dan mencapai target yang ditetapkan (Sari, 2018). Adapun hal yang akan dievaluasi adalah sebagai berikut:

1. Evaluasi dilakukan untuk mengonfirmasi dan memastikan semua data telah lengkap dan sesuai dengan kebutuhan; semua kebutuhan telah tercatat dan memastikan semua fungsionalitas telah sesuai. Hasil wawancara ditandatangani oleh nara sumber untuk memastikan semuanya tidak ada yang salah;

2. Evaluasi dilakukan untuk mengkonfirmasi setiap rancangan sesuai dengan kebutuhan yang diidentifikasi sebelumnya.Dengan demikian, aplikasi dapat langsung dibangun sesuai rancangan tersebut;

3. Evaluasi dilakukan dalam bentuk pengujian aplikasi dengan cara perwakilan pengguna dari kategori anggota ataupun pengurus langsung mencoba menggunakan website. Dengan demikian akan langsung dicatat dan ditindaklanjuti apabila ditemukan error dan fungsi yang tidak sesuai;

4. Evaluasi dilakukan untuk memastikan semua pengguna terlibat dalam pelatihan dan pengimplementasian website.

Adapun tahapan pelaksanaan kegiatan yang pertama sekali dilakukan pada kegiatan pengabdian kepada masyarakat ini yaitu menjelaskan kepada mitra mengenai pemanfaatan website sebagai pendukung kegiatan pemasaran produk unggulan di Kabupaten Bandung. Keberlanjutan kegiatan pengabdian masyarakat diwujudkan dalam bentuk pemeliharaan website oleh tim dari Universitas Telkom dengan alamat (link) domain berikut dispakankabbandung.epizy.com.

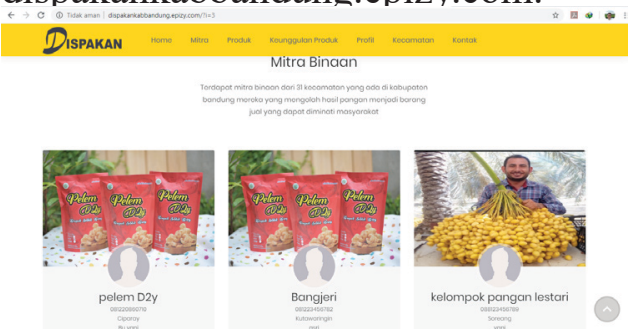

Gambar 1. Tampilan Mitra Binaan Produk Unggulan di Kabupaten Bandung

Adapun jenis layanan yang dimaksud pada kegiatan pengabdian 
kepada masyarakat ini tergolong kategori Business to Consumer (B2C), alasannya karena aktivitas pebisnis (dalam kasus ini yaitu produk unggulan dari para UMKM di Kabupaten Bandung) ini memberikan inventaris berupa website kepada para pelaku usaha yang ada untuk menawarkan produknya kepada customer secara online.
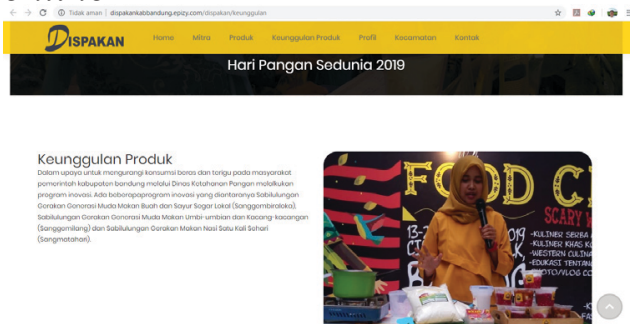

Gambar 2. Tampilan Informasi Edukatif Mengenai Produk Unggulan di Kabupaten Bandung

Bentuk lainnya diwujudkan dalam bentuk pengembangan website untuk mendukung pemasaran produk sehingga peran website tidak hanya pada kegiatan promosi saja, juga dikembangkan untuk transaksi penjualan.

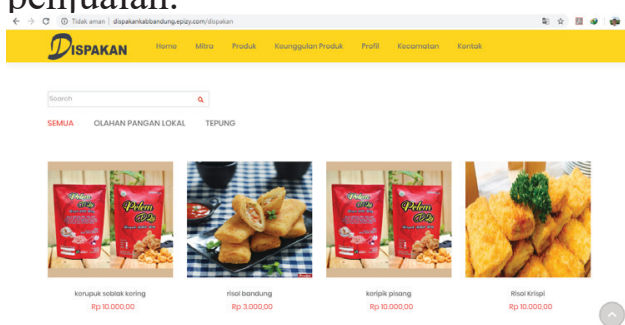

Gambar 3. Tampilan list produk yang dijual atau ditawarkan di Kabupaten Bandung

Adapun beragam ilmu pengetahuan yang telah ditransfer kepada mitra pengabdian masyarakat berupa:

1. Pengetahuan tentang sentralisasi data dengan konsep database;
2. Pengetahuan tentang pengolahan dan data sharing melalui sistem terintegrasi dalam bentuk website;

3. Keterampilan dalam konfirmasi hasil rancangan dan pengujian aplikasi;

4. Produk website berisi profil mitra binaan. Website ini memiliki konten dinamis yang dapat dikelola melalu sebuah content management system;

5. Pengetahuan dan keterampilan pengelolaan konten website dinamis dengan menggunakan content management system.

6. Manajemen produk dan merk (labelling, logo, packaging dan strategi merk), serta pengembangan media branding.

Adapun kegiatan pengabdian kepada masyarakat dalam bentuk pelatihan ini terbuka untuk pelaku UMKM yang menawarkan produk unggulan di Kabupaten Bandung.

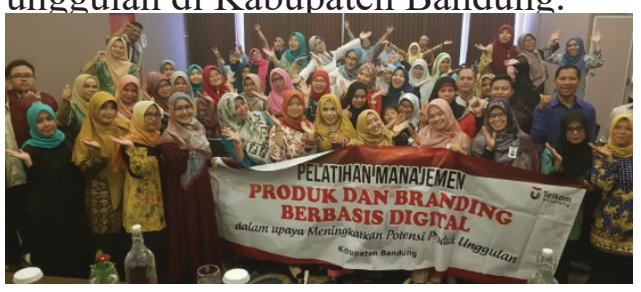

Gambar 4. Pelaksanaan Kegiatan Pelatihan Manajemen Produk dan Branding Berbasis Digital

Tahapan dari pelaksanaan kegiatan ini yakni dengan memberikan pendampingan kepada para UMKM di Kabupaten Bandung yang menyediakan produk unggulan untuk mengetahui tren dan dinamika perkembangan usaha/bisnis serta juga menginventarisir permasalahan yang 
dihadapi oleh para mitra.

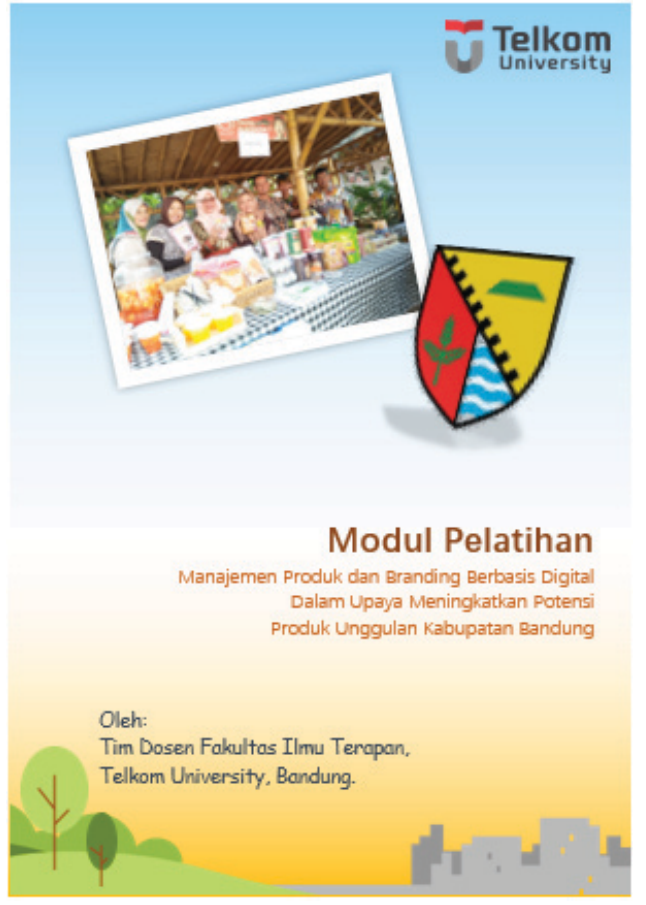

Gambar 5. Modul Pelatihan

Manajemen Produk dan Branding

Berbasis Digital

Proses selanjutnya, dilakukan pelatihan mengenai manajemen produk dan branding berbasis digital yang juga disertai buku modul pelatihannya. Adapun tahap pelaksanaan ini dilakukan dengan pengadaan pelatihan cara pembuatan merk dan logo serta desain dan layout produk yang lebih menarik, karena sebelumnya mitra hanya mengemas produk ala kadarnya, sangat sederhana dan tanpa disertai merk.

Berdasarkan hasil tatap muka langsung dengan mitra sasar pada saat pelaksanaan, diperoleh informasi partisipasi dan keterlibatan mitra pada setiap tahapan, yaitu:

1. Sebagai narasumber pada wawancara untuk mendapatkan data berupa profil Dinas Ketahanan Pangan dan mitra binaannya; struktur dan format data mitra binaan yang dimiliki oleh dinas; permasalahan yang dihadapi dinas dalam pengelolaan data dan profil mitra binaan; dan kebutuhan fungsionalitas atau fitur yang harus dimiliki oleh website untuk pengelolaan data dan profil mitra binaan ataupun pengurusnya;

2. Sebagai verifikator semua rancangan yang telah dibuat untuk meastikan bahwa semua rancangan mengakomodir kebutuhan pengguna;

3. Sebagai penguji aplikasi berbasis web pada tahapan pengujian website untuk memastikan bahwa semua fungsionalitas yang disediakan untuk pengguna telah valid. Pengujian dilakukan dengan menggunakan metode User Acceptance Test (UAT);

4. Sebagai peserta sekaligus agen perubahan pada implementasi atau penerapan website untuk memastikan semua anggota ataupun pengurus aktif menggunakan website sebagai sarana untuk komunikasi data dan promosi produk.

5. Sebagai peserta pada pelatihan dan workshop manajemen produk dan merk (labelling, logo, packaging dan strategi merk), serta pengembangan media branding.

6. Mengimplementasikan hasil workshop pada produk olahan masing-masing sehingga produk lebih menarik dan bernilai jual tinggi. 


\section{SIMPULAN}

Berdasarkan uraian sebelum nya, implementasi dari program pengabdian kepada masyarakat yang telah terlaksana adalah sebagai berikut. Aplikasi berbasis web untuk mengelola database mitra binaan Dinas Pangan yang sudah siap diimplementasakan. Di samping itu, aplikasi berbasis web tersebut juga dapat digunakan oleh para pelaku UMKM sebagai sarana pemasaran hasil produksi di Kabupaten Bandung atau yang biasa dikenal dengan sebutan produk unggulan. Adapun website tersebut berfungsi untuk menjembatani para pelaku UMKM dengan Dinas Ketahanan Pangan dan juga terhadap para calon konsumen nya untuk mempromosikan produkproduk unggulan masing-masing UMKM di Kabupaten Bandung. Website yang beralamatkan di https:// dispakankabbandung.epizy.com/ merupakan website yang dapat diakses dengan mudah oleh pelaku UMKM karena dapat diakses menggunakan handphone, laptop, maupun perangkat gadget lainnya. Hal ini tentunya akan meningkatkan nilai tambah dari website tersebut karena dapat diakses dimana dan kapan saja tanpa adanya tambahan biaya ataupun alat khusus untuk mengoperasikannya.

Selain penyediaan website tersebut, juga sudah terlaksananya kegiatan sosialisasi dan pelatihan penggunaan aplikasi berbasis web kepada mitra binaan dan Dinas Pangan dalam bentuk presentasi dan modul pengoperasian aplikasi. Selanjutnya juga dipaparkan materi peletihan dalam hal manajemen produk dan merk (branding strategy) sehingga produk yang dihasilkan memiliki nilai jual yang tinggi serta diharapkan mampu meningkatkan pemahaman para mitra binaan. Di samping itu, diharapkan program ini juga mampu meningkatkan pemahaman dan kesadaran masyarakat tentang makanan sehat berbahan dasar tepung mocaf.

\section{DAFTAR PUSTAKA}

Arifanty, L. D. (2018). Branding UMKM (usaha mikro dan kecil menengah) Terang Bulan Crispy Affan di Kelurahan Mojo (Doctoral dissertation, UIN Sunan Ampel Surabaya).

Budiarto, R., Putero, S. H., Suyatna, H., Astuti, P., Saptoadi, H., Ridwan, M. M., \& Susilo, B. (2018). Pengembangan UMKM Antara Konseptual dan Pengalaman Praktis. UGM PRESS.

Mahmudi, A. A., \& Suryandani, W. (2018). Strategi Pengembangan UKM Keripik Tempe Desa Tahunan Kecamatan Sale Kabupaten Rembang. In Prosiding Seminar Nasional Unimus (Vol. 1).

Nugraha, A. E. P., \& Wahyuhastuti, N. (2017). Start up digital business: sebagai solusi penggerak wirausaha muda. Jurnal Nusantara Aplikasi Manajemen Bisnis, 2(1), 1-9.

Nurlina, L., Alim, S., Sulistyati, M., \& Fitri, E. (2017). Kapasitas Wanita Tani Ternak Dalam Pemanfaatan Pupuk Organik (Kasus pada Program Kawasan Rumah Pangan Lestari Di Kelompok Wanita Tani Harja Rahayu di Desa Raharja Kecamatan Tanjungsari Kabupaten Sumedang). In 
Prosiding Seminar Teknologi Agribisnis Peternakan (STAP)

FakultasPeternakanUniversitas Jenderal Soedirman (Vol. 5, pp. 408-414).

Paramita, A., \& Kristiana, L. (2013). Teknik Focus Group Discussion Dalam Penelitian Kualitatif. Buletin Penelitian Sistem Kesehatan, 16(2 Apr).

Purwantini, T. B., Saptana, S., \& Suharyono, S. (2016). Program kawasan rumah pangan lestari (KRPL) di Kabupaten Pacitan: analisis dampak dan antisipasi ke depan. Analisis Kebijakan Pertanian, 10(3), 239-256.

Safitri, N. W. (2016). Penerapan E-Government di Pusat Pelayanan informasi dan Pengaduan Kabupaten Pinrang (Doctoral dissertation, Universitas Hasanuddin).

Sari, P. (2018). Evaluasi pelaksanaan revitalisasi posyandu dan pelatihan kader sebagai bentuk pengabdian masyarakat (Studi Kasus Di Rw 06 Desa Cileles Kecamatan Jatinangor Tahun 2017). Jurnal Pengabdian Kepada Masyarakat, 2(2), 9397.

Sudarwati, Y., \& Satya, V. E. (2013). Strategi pengembangan merek usaha mikro, kecil, dan menengah. Jurnal Ekonomi dan Kebijakan Publik, 4(1), 89-101. 